\title{
An Empirical Study on Successful-Intelligence- Based College English Instructional Mode in China
}

\author{
Huang Huannai \\ School of International Studies \\ Xi'an Technological University \\ $\mathrm{Xi}^{\prime}$ an, China \\ 915677282@qq.com
}

\author{
Sunlei \\ School of International Studies \\ Xi'an Technological University \\ $\mathrm{Xi}$ ' an, China \\ 88308721@qq.com
}

\begin{abstract}
To establish whether Successful-Intelligence-based instructional mode may arouse students' interests in college English learning and other positive influences on their English academic achievements, this paper, aiming at the cultivation of students' analytical, creative, and practical intelligence, highlights the diversified classroom activities in ELT by quantitative and qualitative methods on three pairs of empirical (187 non-English majors) and controlled classes (196 non-English majors) in XATU in SI-based and traditional approaches respectively, which indicates a distinct difference $(36.85)$ of the two sets of the results of post-test CET-4. The results we expected and obtained demonstrated that the SI-based English activities has not merely made lessons more interesting but also stirred post-90s' college students' interest, confidence and cooperative consciousness, and achieved students-centered teaching atmosphere. For the limited sample of subjects, much room still leaves for deeper field research and some follow-up studies are necessary for further investigation into this area. Exciting new research has elaborated several crucial findings that provide pedagogical implications for English teaching in Chinese university as well as the evidence that the hypothesis integrating the SI into the college English teaching promotes English learning and increases participants' confidence so as to enhance their English proficiency and ability to use English in a wellrounded way.
\end{abstract}

Keywords-Successful Intelligence Theory; SI-based instructional mode; College English teaching; Academic achievements

\section{INTRODUCTION}

\section{A. New era, new situation}

The expansion of college enrollment in 1999 and its continuation for the following few years have called for new education reforms and new education modes, among which college English teaching and learning mode is of the first significance. New college English teaching modes of qualityoriented rather than examination-oriented have been widely practiced for non-English majors of science and technology since the official publishing of College English Curriculum Requirements [1] to adjust to the new requirements of China's higher education developments, deepening the reforms of teaching and learning as well as improving the quality of teaching and learning so as to meet the needs of individual training in the new era.

College English Curriculum Requirements clarifies exhaustively that "the objective of College English is to develop students' ability to use English in a well-rounded way, especially in listening and speaking, so that in their future studies and careers as well as social interactions they will be able to communicate effectively, and at the same time enhance their ability to study independently and improve their general cultural awareness so as to meet the needs of China's social development and international exchanges."

The successful intelligence (SI) theory[2], developed by Robert J. Sternberg, an American psychologist and psychometrician, currently a professor of Human Development at Cornell University, is well consistent with demand of the College English Curriculum Requirements, which emphasizes the education for all-round development. The application of this important theory advocating analytical intelligence, creative intelligence, and practical intelligence, is possibly a promising access to distinguishing students respond to English learning in the SI-based instructional mode; testifying SI-based instructional mode may arouse students' interests in college English learning and will not have negative influence on their English achievement; examining that is there any correlation between the English academic achievement and successful intelligence of these students; and figuring out the benefits teachers find in applying SI-based instructional mode to college English teaching and learning.

\section{B. Background}

Great contributions with the application of SI theory in education in western countries have been done by experts and scholars while only connection of this theory with the education of kindergarten and high school learners, and few tentative studies in college English teaching and learning in China, have been investigated. Therefore, this empirical research is under investigation being taken account of the lack of empirical studies of SI theory on non-English majors.

As an organic whole, SI is composed of analytical, creative, and practical intelligence, also known as the triarchic theory of intelligence [3]. He mentioned that cognitive development can be fully understood only if one looks beyond one's own cultural boundaries and preconceptions [4]. Being essential for 
solving problems, analytical intelligence is capability for completing academic, problem-solving tasks, such as those used in traditional intelligence tests. Analysis of the problem, which is for having only a single correct answer, is to develop a set of criteria by which to judge possible and potential solution and to resolve the issue successfully. Without this type of intelligence, possible solutions for the pros and cons to determine which one might work best could not be checked and balanced or weighed.

Often helping individuals to transfer information from one problem to another, creative intelligence is the capability for successfully dealing with new and unusual or tough and really difficult situations by applying the existing knowledge and skills. Creative intelligence calls for generating multiple solutions, by going beyond the immediate, taking in the big picture, and determining which problem to solve. Association with used knowledge and skills or seemingly unrelated information often makes the real and tough problem to surface.

Practical intelligence is the capability for selecting and shaping their environment [5] that is not represented by traditional measures of giftedness, or adapting to everyday life by drawing on existing knowledge and skills, or picking up tacit information and utilizing that information. By making an individual to understand what needs to be done in a specific setting and then do it, Practical intelligence enables them to shape their environment around them and bring theory into practice. Practical intelligence states the value of the idea and increases the likelihood of success.

\section{Methodology}

The methodology, employed in this experiment, is made up of the hypotheses, subjects, the specific methodology and procedures as well as data collection. Both quantitative and qualitative methods will be used together as both of them have merits and shortcomings respectively in the research. The results of the authoritative College Entrance English Examination (CEEE) was as the result of pre-test and another two language tests(Final-term exam and CET-4) would be held during the teaching experiment so as to testify the reliability of this subject.

The hypotheses are: the SI-based College English instructional mode can arouse students' interests so as to improve students' academic achievements; the SI-College English instructional mode works more effectively than the traditional way in improving students' academic achievements. That is, students in the experimental class can make greater progress in this English proficiency on account of SI-based college English instructional mode. An experiment was designed and carried out in order to testify the hypotheses.

The subjects of this study involved, 383 first-year nonEnglish majors who just have passed the College Entrance Examination (CEE) in 2012, six classes in Xi'an Technological University (XATU). Three classes functioned as the experimental class (EC) participates in the teaching experiment, 187 of EC are all from the science and technology and are taking SI model as the principal teaching and learning method; the other classes, majoring in the same school as the

This paper is the final for the Project (SGH12455, 2012) of the Twelfth Five-year Program Office of the Shaanxi Provincial Government, China. experimental classes, functioned as the controlled classes (CC) with 196 students under the traditional teacher-oriented situation. The experiment, lasted two semesters, was carried out from September to June of the year 2012 to 2013 in the EC., The results of the pretest show us the academic achievement of the experimental classes is no significant difference than that of the controlled classes.

The research, at first, collected the scores of CEEE at the beginning of the experiment. The scores of the students in six classes are collected as the pre-test data. So are the scores of the mid-term examination, two finals. Then, with the same teaching materials-New Horizon College English (second version) as textbook, the research conducts the teaching activities by mainly adopting SI-based instructional mode in the experimental class and traditional way in controlled class. Every pair of the EC and CC classes are taught by the same teachers for two academic terms. The experiment lasted two academic terms from September, 2012 to July, 2013. The two different language teaching and learning modes - adopting the theory of SI to conduct the English teaching and traditional English teaching methods are compared to testify which is better.

The specific methodology and procedure of SI-based instructional mode is conducted through the following three ways mainly:

1) the analytical intelligence is cultivated by way of comparative analysis and question teaching;

2) the creative intelligence is cultivated by way of cultivating students' imagination, developing students' divergent and convergent thinking, and comprehensively training students' convergent thinking and divergent thinking;

3) the practical intelligence is Cultivated by way of text expansion combined with English practical ability and combining the comprehensive learning and enhancing their English practical ability.

\section{RESULTS AND ANALYSIS}

All these tests were language proficiency tests with high validity and reliability which could offer us more accurate data for the comparison on the students' academic achievements in college English study.

TABle I. Group Statistics OF Tests Between EC \& CC

\begin{tabular}{c|c|c|c}
\hline $\begin{array}{c}\text { Pre-test \& } \\
\text { While-test }\end{array}$ & Mean of EC & $\begin{array}{c}\text { Mean of } \\
\text { CC }\end{array}$ & Mean Deviation \\
\hline CEEE & 106.0 & 106.5 & -0.5 \\
\hline & 105.1 & 105.2 & -0.1 \\
\hline Total deviation & 102.8 & 102.5 & 0.3 \\
\hline Final test & 67.37 & 64.72 & 0.1 \\
\hline & 65.18 & 62.34 & 2.65 \\
\hline & 68.92 & 64.19 & 2.84 \\
\hline Total deviation & & & 4.73 \\
\hline
\end{tabular}


Obviously, Table I displays the mean value in tests between EC and CC classes. It can be seen from the table that the gap between EC and CC in pre-test is not quite wide apart, however, to our content, based on one academic year empirical learning, students gained higher (10.22) mean scores in the while-test.

Whether SI-based mode of instruction is more effective than the traditional one, more analysis needs to be done. In the following table, contrast on the scores in post-test is established by the researcher. (See Table II)

The column of Mean value indicates a distinct difference (36.85) of the two sets of the results of CET-4, which testifies the feasibility of this empirical study.

Compared with the traditional teaching model, students have access to getting more opportunities to engage in class activities, which can put their language abilities into full play. It is likely to motivate learners by activating multiple ways through the use of tasks in the SI classroom.

TABLE II. Group Statistics in Post-Test Between EC \& CC

\begin{tabular}{|c|c|c|c|}
\hline & Mean of & Mean of & \\
\hline Post-test & $\mathrm{EC}$ & $\mathrm{CC}$ & Mean Deviation \\
\hline \multirow{3}{*}{ CET-4 } & 406.79 & 394.76 & 12.03 \\
\hline & 410.58 & 390.86 & 19.72 \\
\hline & 394.37 & 389.27 & 5.1 \\
\hline \multicolumn{3}{|l|}{ Total deviation } & 36.85 \\
\hline
\end{tabular}

SI based college English instructional mode creates a positive atmosphere in which the student-centered teaching model takes the place of the teacher-centered one. Students, instead of being passive knowledge receivers, become the master and actual participant in class activities. They are full of enthusiasm, courage, motivation and interest to engage in those activities. Motivation should be considered as an inner force of accomplishments [6]. The above results testify the fresh mode exerts a positive impact on students' confidence and self-esteem. Therefore, to some extent, each student is received concern and praise from their teacher and group members which encourage them to do better than before. In addition, the entire experimental class is more active, confident and cooperative in English class than those controlled class which positively influence on language learning, thus improves their comprehensive ability.

It is distinguished that people learn in different ways. Undoubtedly, in one period lesson, it is not feasible to please and cater every student all the time but instructors are able to endeavor and stimulate as much as possible, therefore, teachers should try to use different activities. A brief model is like this:
- Text:

Unit 1 Learning A Foreign Language New Horizon College English (Second Edition, 2008) Book 1, Foreign Language Teaching and Research Press

- Teaching Allotment:

1st period: Warm-up Activities \& While-reading Activities

2nd period: While-reading Activities

3rd period: After-reading Activities

4th period: Text Structure Analysis and Review

- Methodology:

Lecture with SI-based group work and discussion; Multimedia and blackboard

- Teaching Procedures:

Task 1: Warm-up Activities and Lead-in

Step 1: Enable Ss to talk about their experiences of learning English. (Analytical intelligence)

Step 2: One plays the role of the teacher in high school. The other members are the students. The teacher gives lesson to the students. (Practical intelligence)

Task 2: While-reading and understanding

Step 1: Check students' preview work to present the main idea of the text; and analyze the style and structure of the passage by the aid of the teacher. (Creative \& Practical intelligence)

Step 2: Allow all the students listen to the record twice to get the main idea of the text and answer several questions. (AI)

Step 3: Raise questions over the text. (AI) Explain and enlighten new words, phrases and difficult sentences and patterns. (PI)

Task 3: Post-reading and act out

Step 1: Suppose you are the author. Work with your partners to talk about your experiences of learning English at different stages in time order, including benefits of learning English. (CI \& PI)

\section{Step 2: Idea Sharing:}

How did your English teacher in middle school or primary school behave in class? How do you expect your college English teacher to manage his or her class? Watch the video clips and then discuss. (AI \& CI)

\section{CONCLUSION}

Under the guidance of this fresh teaching method, the empirical study provides pedagogical implications for English teaching in Chinese university, especially for Xi'an Technological University. Based on the application of Sternberg's SI theory, this empirical study was carried out as a stimulus to motivate non-English majors' English learning. The result of the empirical study gives the evidence that the 
hypothesis integrating the SI into the college English class promotes English learning and increases participants' confidence so as to improve their English proficiency as well as to develop students' ability to use English in a well-rounded way. Therefore, to a large degree, the SI exerts a significant and positive influence on English teaching as well as learning in the long run.

Compared with the traditional teaching method, the incorporation with SI and ELT will be more effective to stimulate students' motivation and interest as well as promote their academic achievements. The researcher, consequently, does hope this study can make some enlightenment to both teachers and language learners in the future.

\section{REFERENCES}

[1] Higher Education Department of Ministry of Education. College English Curriculum Requirements. Shanghai Foreign Language Education Press, Shanghai, 2007

[2] Sternberg, R. J. Giftedness according to the theory of successful intelligence. In: Colangelo N, Davis GA (eds) Handbook of gifted education. Allyn and Bacon, Boston, 2003: 88-99.

[3] Sternberg, R. J. The Theory of Successful Intelligence Interamerican Journal of Psychology - 2005(39) Num. 2: 189-200

[4] Sternberg, R. J. The development of adaptive competence: Why cultural psychology is necessary and not just nice [J]. Developmental Review, 2014( 34): 208-224

[5] Sternberg, R. J. et al. The Relationship between Academic and Practical Intelligence: a Case Study in Kenya [J]. Intelligence, 2001, (29): 401418.

[6] Ayşe Esra Aslan, Berke Kirikkanat. Achievement and Motivation: A Different Perspective on Familiar Concepts[J]. Procedia - Social and Behavioral Sciences, 2013(106):308-316 